\title{
Comparison of ERA5 and ERA-Interim near-surface air temperature, snowfall and precipitation over Arctic sea ice: effects on sea ice thermodynamics and evolution
}

Caixin Wang et al.

Correspondence to: Caixin Wang (caixin.wang@npolar.no)

The copyright of individual parts of the supplement might differ from the CC BY 4.0 License. 

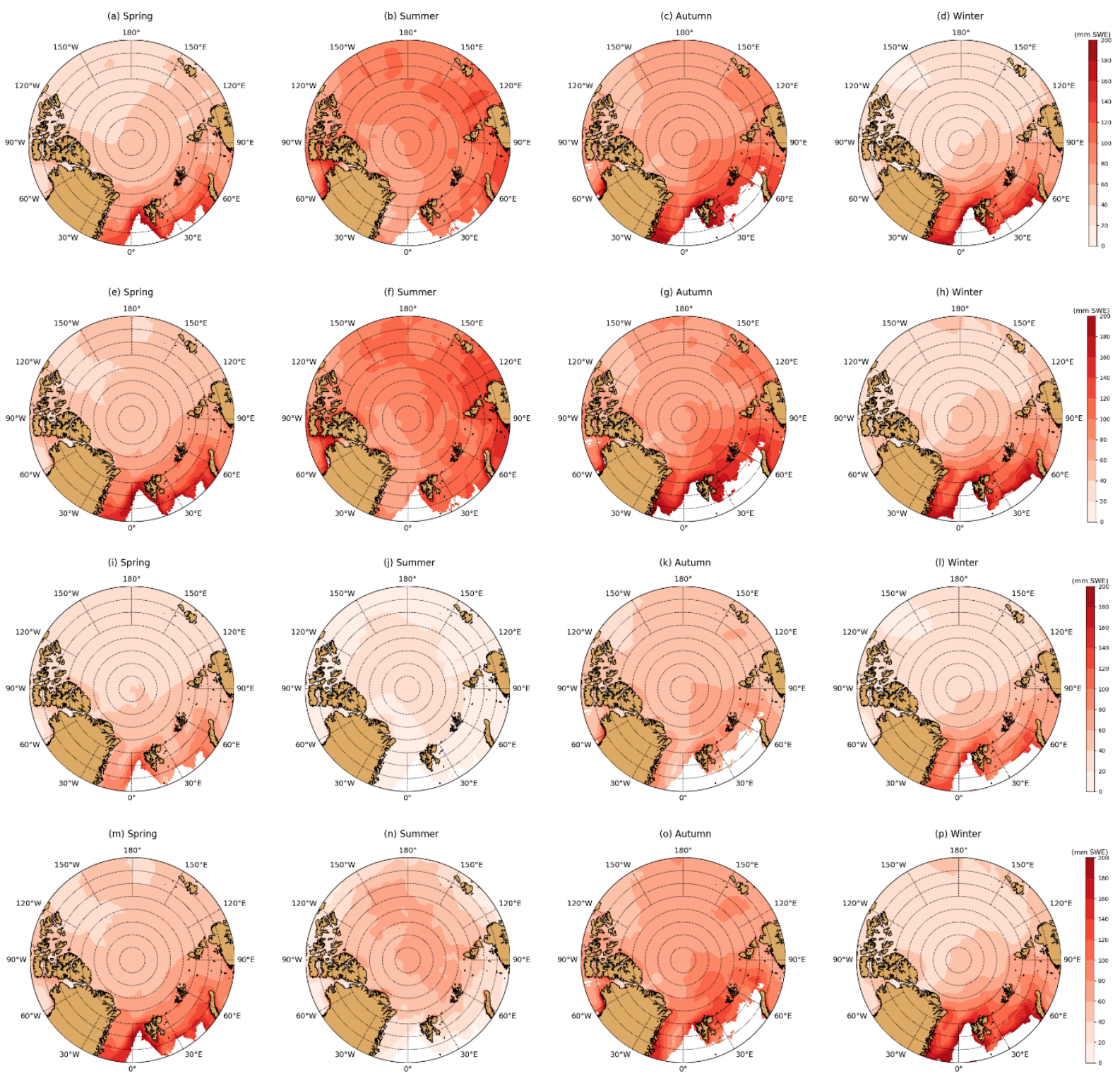

Figure S1. Seasonal mean total precipitation (TP) for ERA-I (a-d) and ERA5 (e-h), and seasonal mean snowfall (SF) for ERA-I (i-l) and ERA5 (m-p) in spring (a, e, i, m), summer $(b, f, j, n)$, autumn $(c, g, k, o)$ and winter $(d, h, l, p)$ over Arctic sea ice for 2010-2015. 

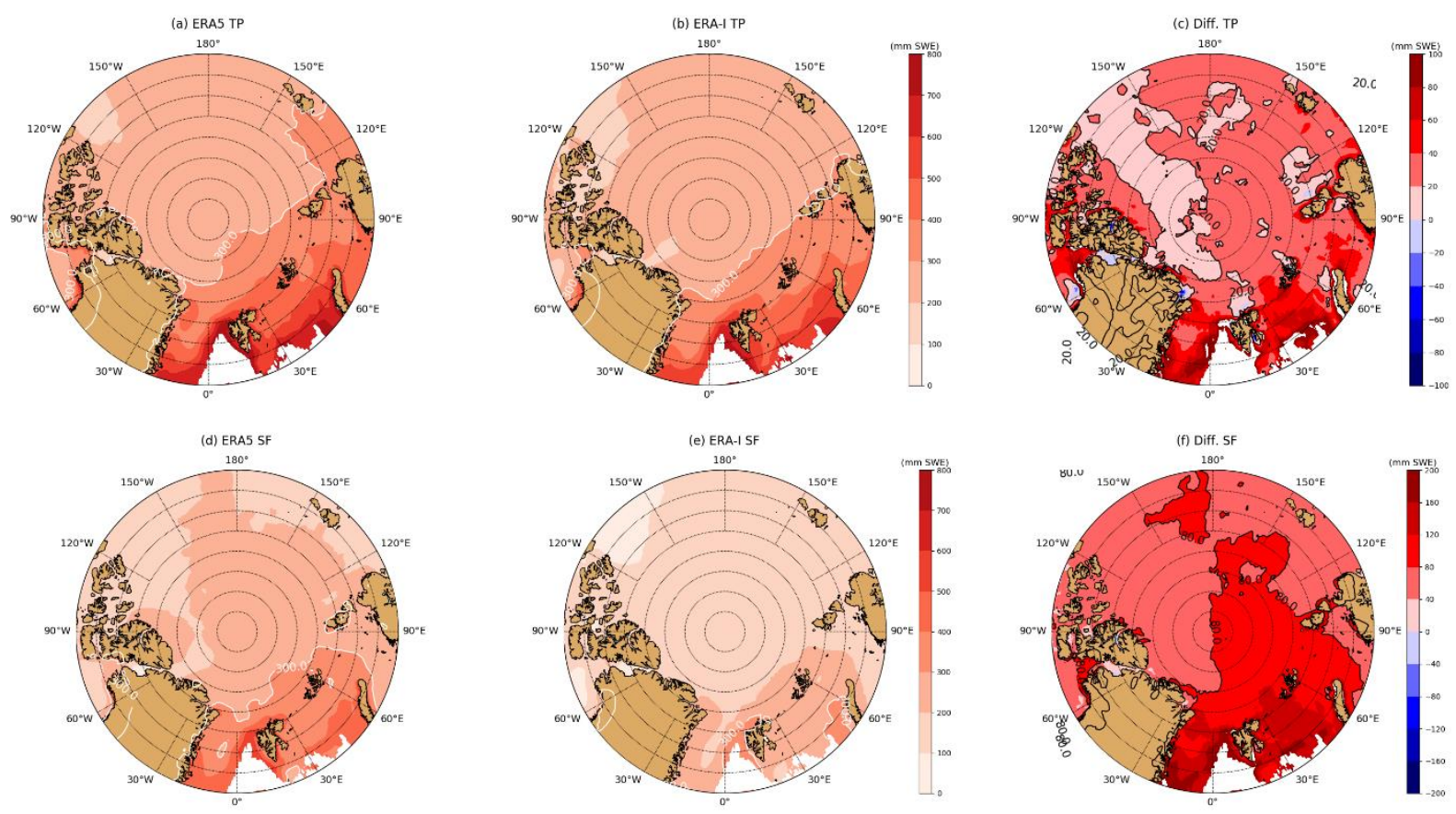

Figure S2. Annual total precipitation (TP) (a-c) and snowfall (SF) (d-f) for ERA5 (a, d), ERA-I (b, e) and their differences (ERA5 minus ERA-I) (c, f) over Arctic sea ice for 2010-2015. 

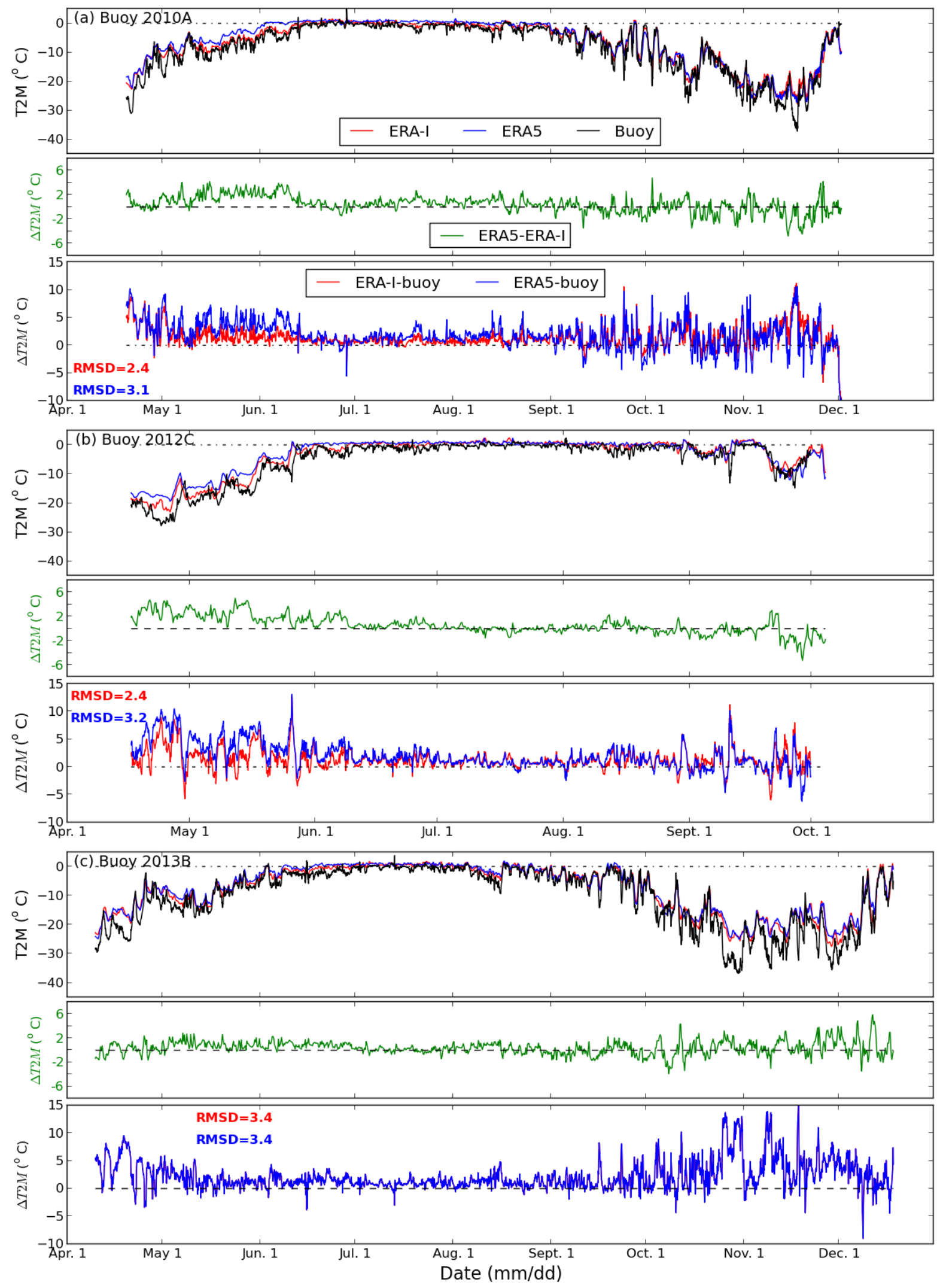

Figure S3. Variation of $2 \mathrm{~m}$ air temperature (T2M) in ERA5, ERA-I and the buoys (upper panel) and the differences of T2M between ERA5 and ERA-I (mid-panel; green color) and comparisons for ERA5 and ERA-I with buoys (ERA5 minus buoy; ERA-I minus buoy) for buoys (a) 2010A, (b) 2012C, and (c) 2013B. RMSD values for the comparison between ERA products and buoys are shown as text, blue for ERA5-buoy, red for ERA-I-buoy. Note the different time-axis. 


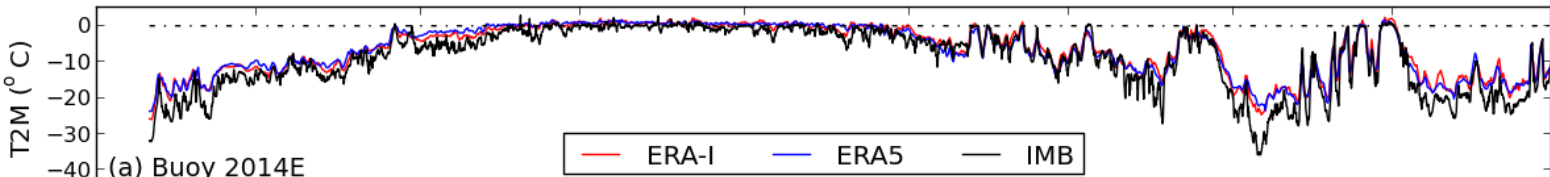

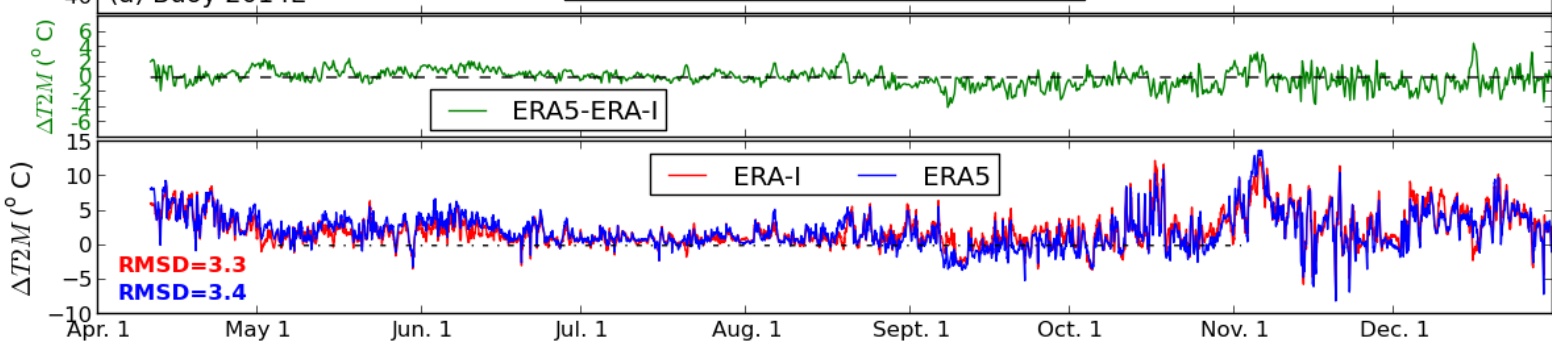

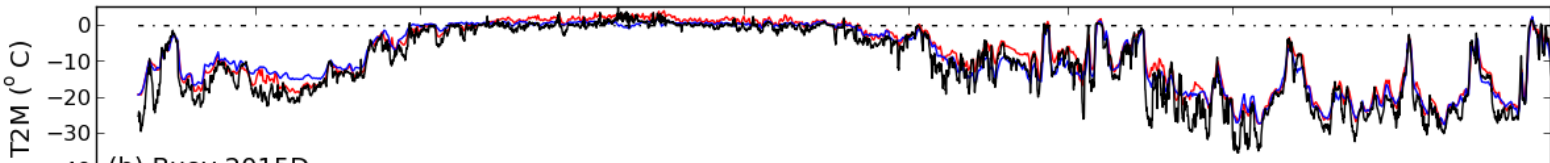

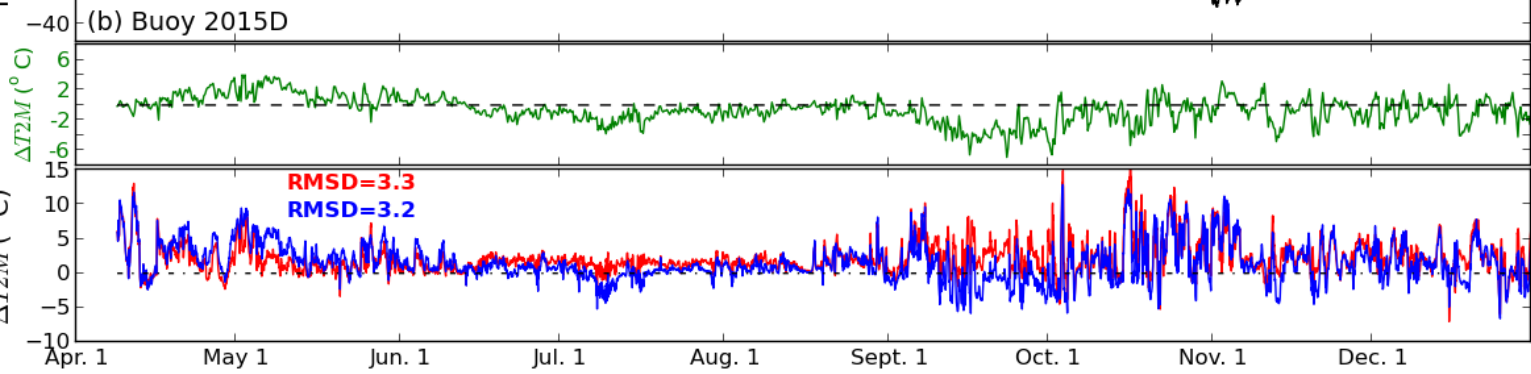

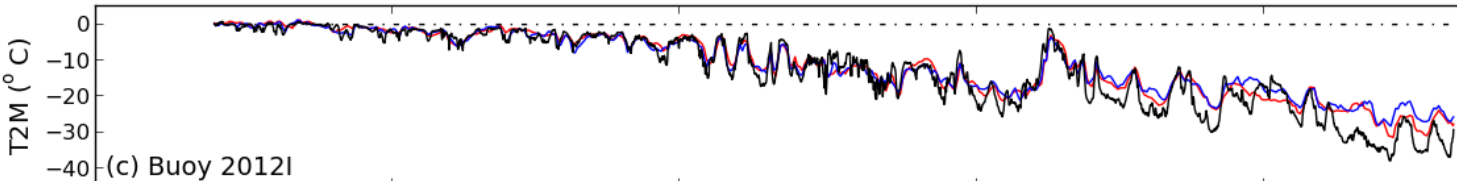

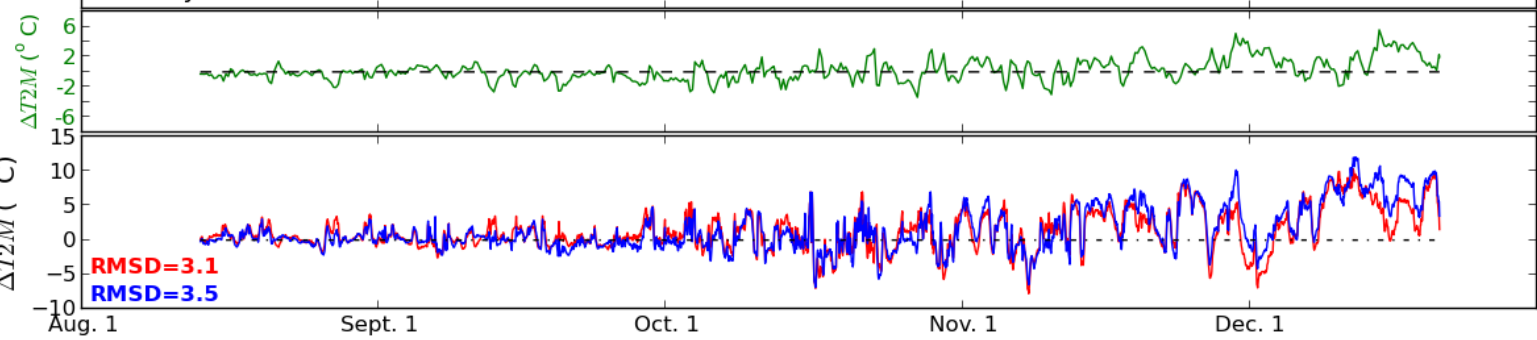

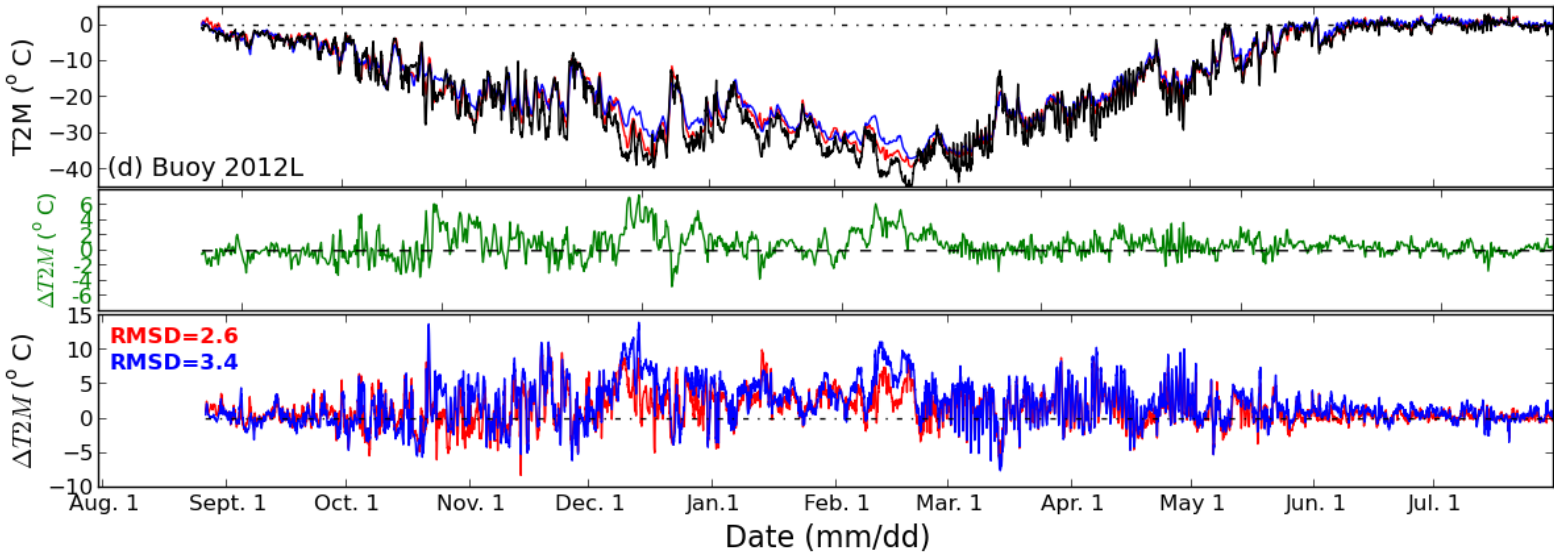

Figure S4. Same as Figure S3, but for buoys (a) 2014E, (b) 2015D, (c) 2012I, and (d) 2012L. Note the different timeaxis. 

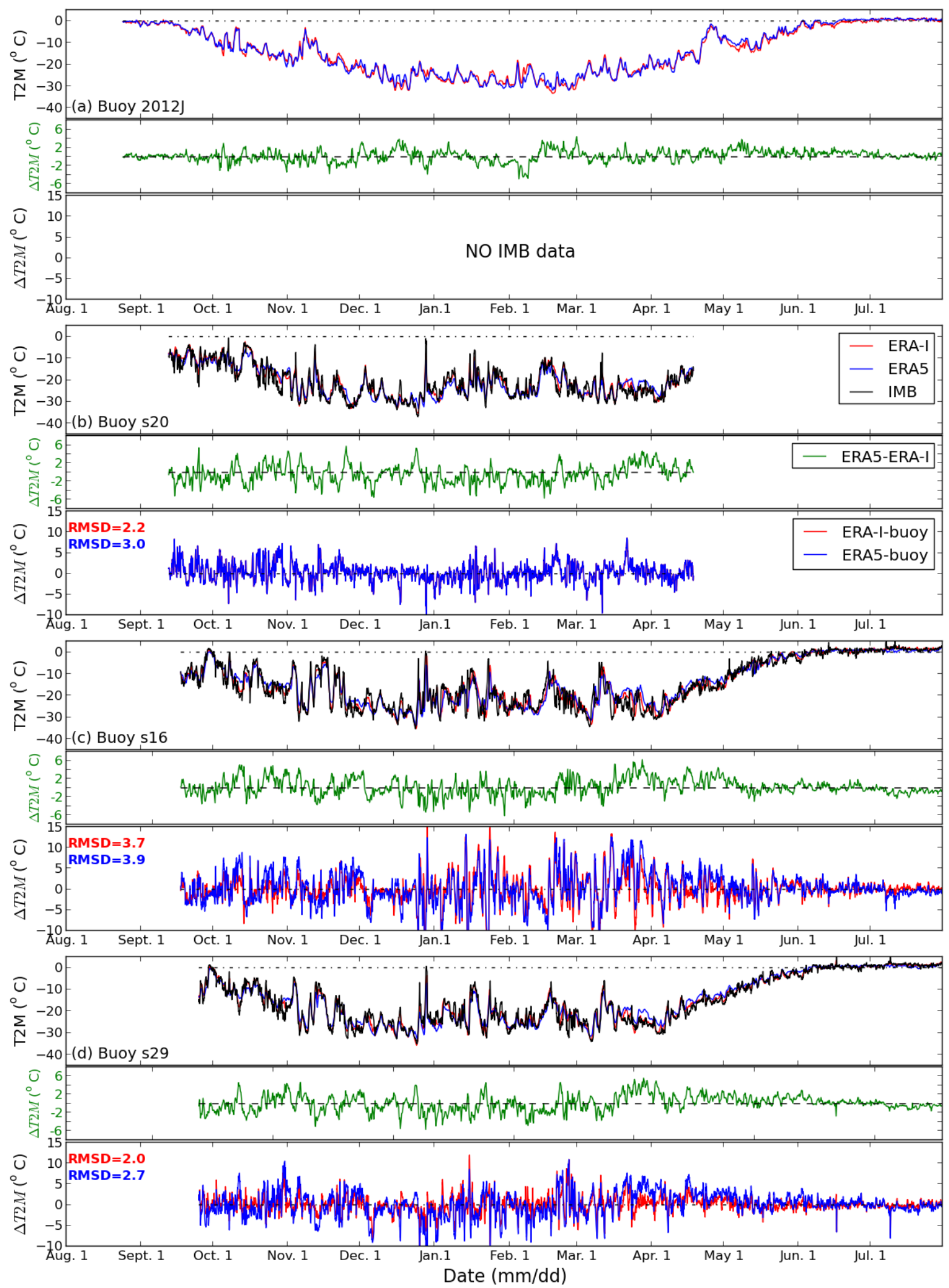

Figure S5. Same as Figure S3, but for buoys (a) 2012J, (b) s20, (c) s16, and (d) s29. 

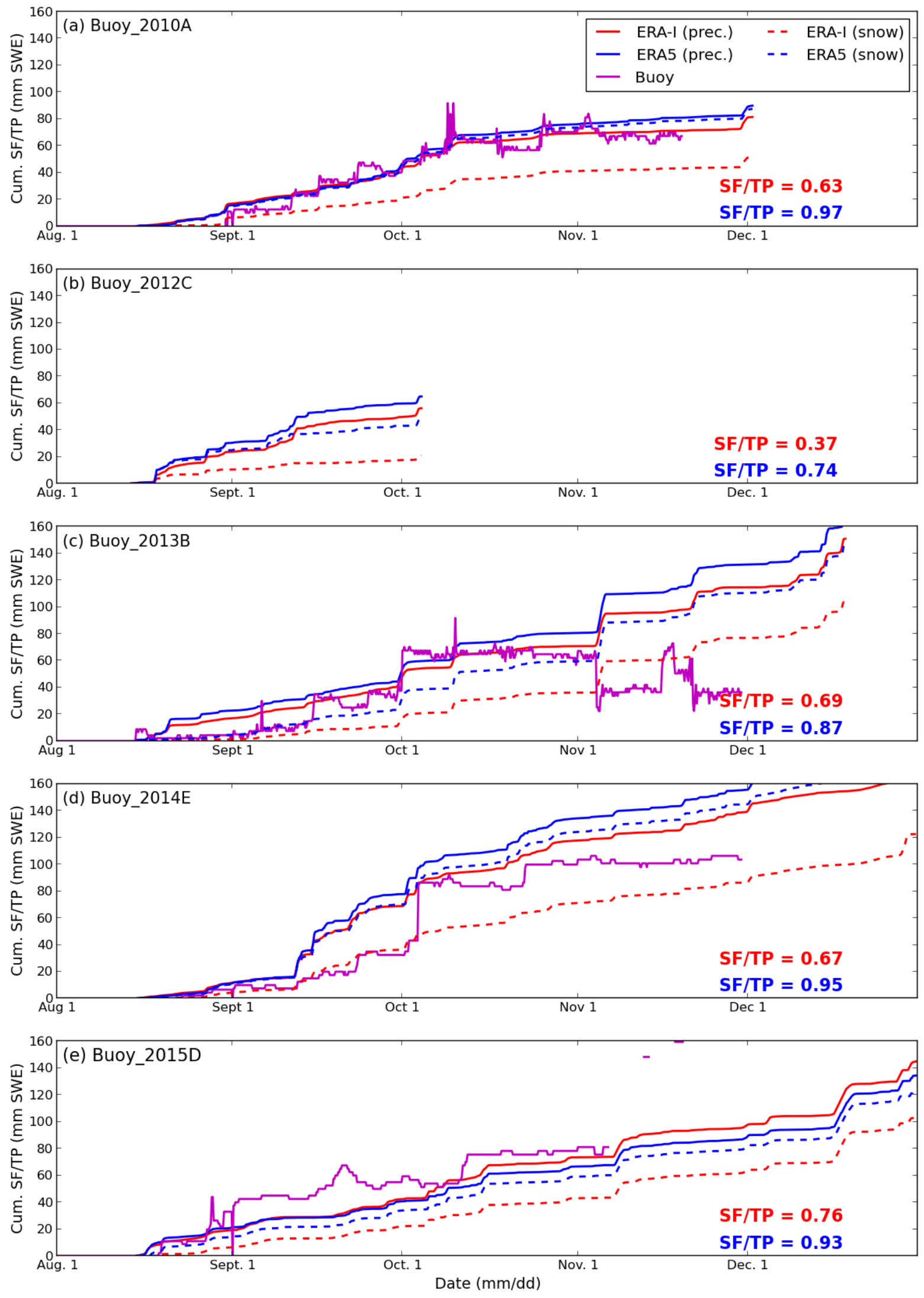

Figure S6. Cumulative total precipitation (TP) and snowfall (SF) for ERA5 and ERA-I and snow depth for buoys (a) 2010A, (b) 2012C, (c) 2013B, (d) 2014E, and (e) 2015D. Accumulation starts from 15 August. The ratio of snowfall to total precipitation (SF/TP) in ERA5 (blue text) and ERA-I (red text) is also shown in the figure. Note that Buoy_2012C does not have snow depth data. 

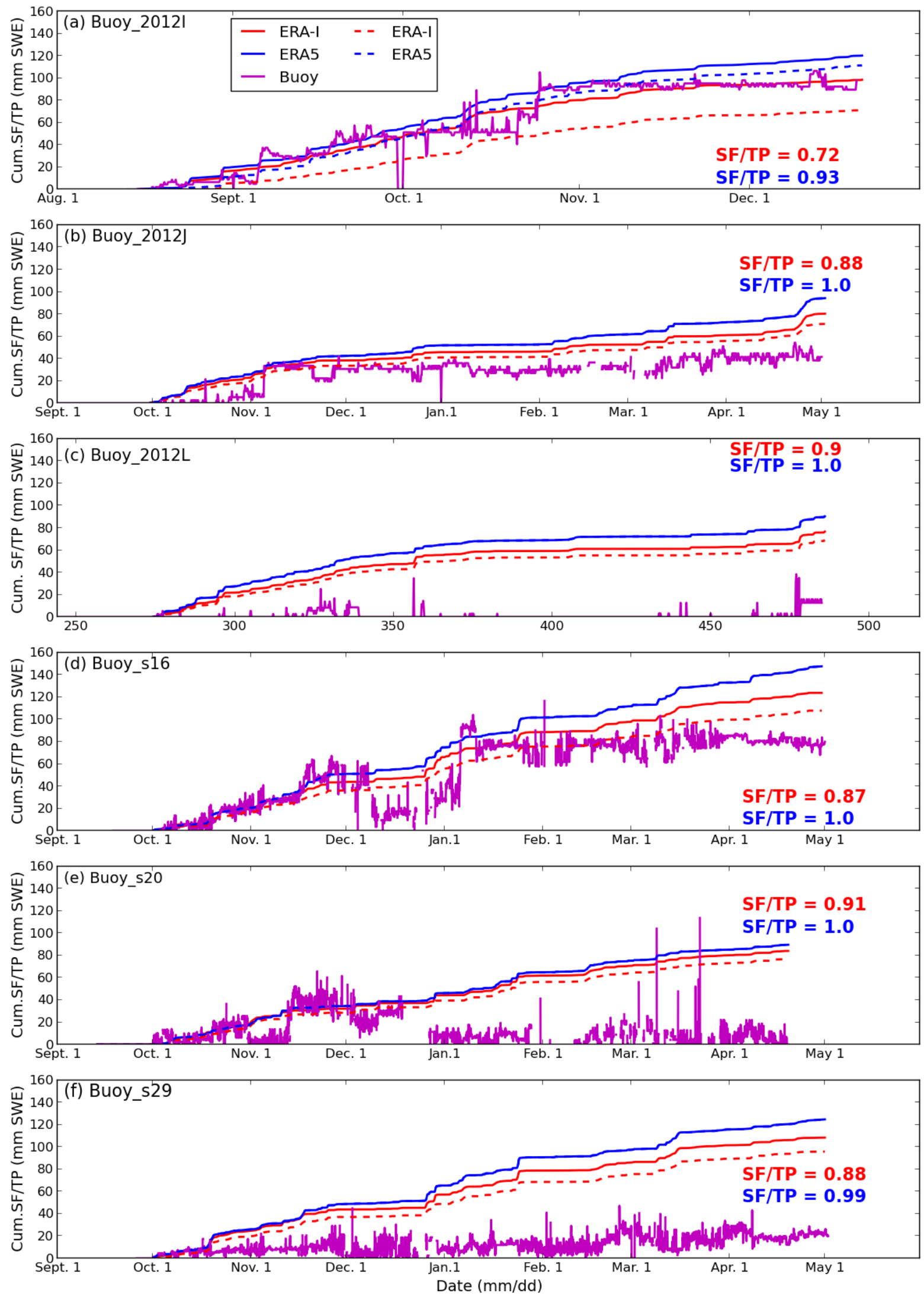

Figure S7. Same as Figure S6, but for buoys (a) 2012I, (b) 2012J, (c) 2012L, (d) s16, (e) s20, and (f) s29, and accumulation starts on 15 August for (a) and starts on 1 October for (b)-(f). 

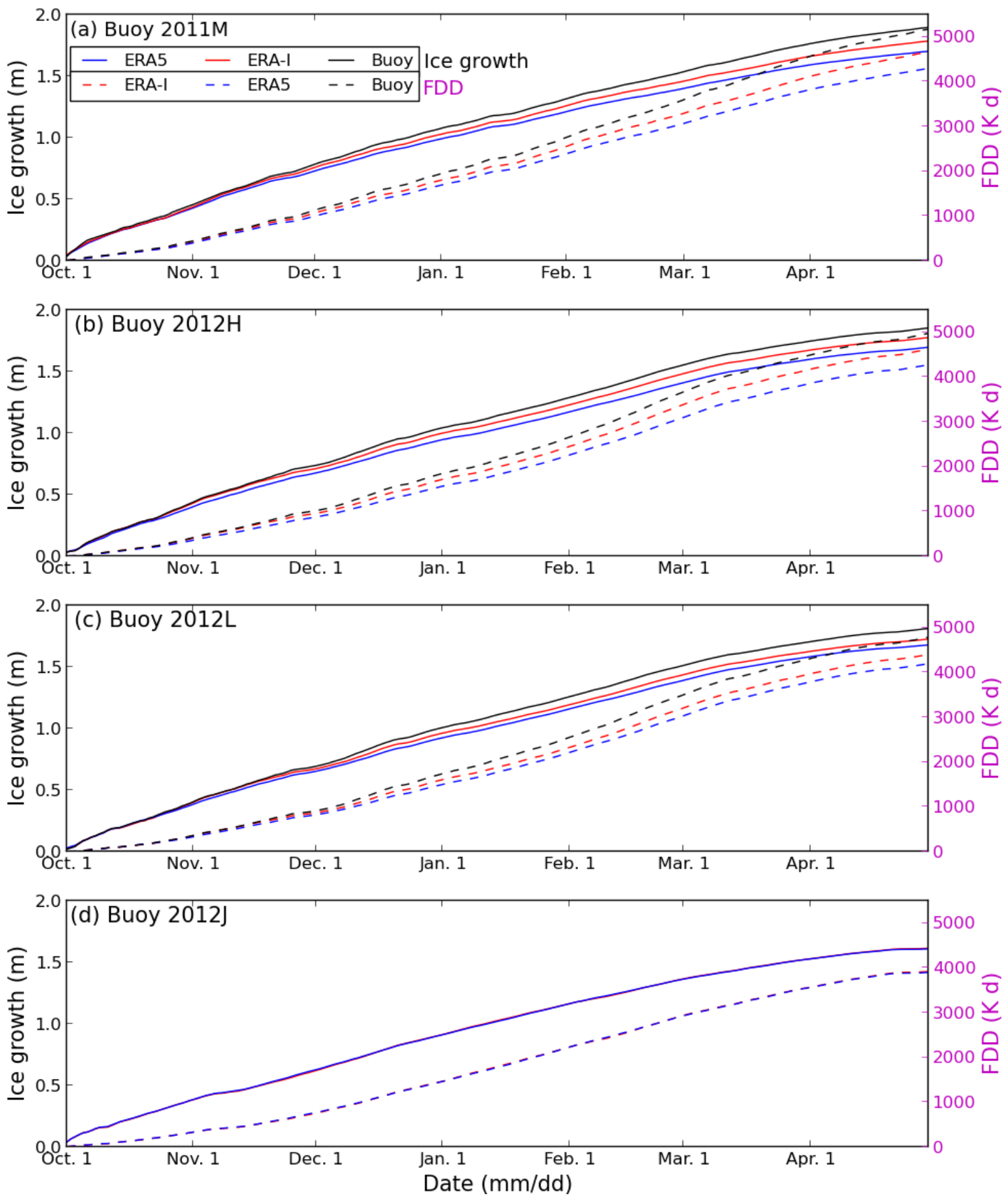

Figure S8. Cumulative FDD and estimated ice growth using cumulative FDD model along the trajectories of (a) buoy 2011M, (b) buoy 2012H, (c) buoy 2012L, and (d) buoy 2012J for freeze-up from 1 October. 
(a) $2012 \mathrm{H}$
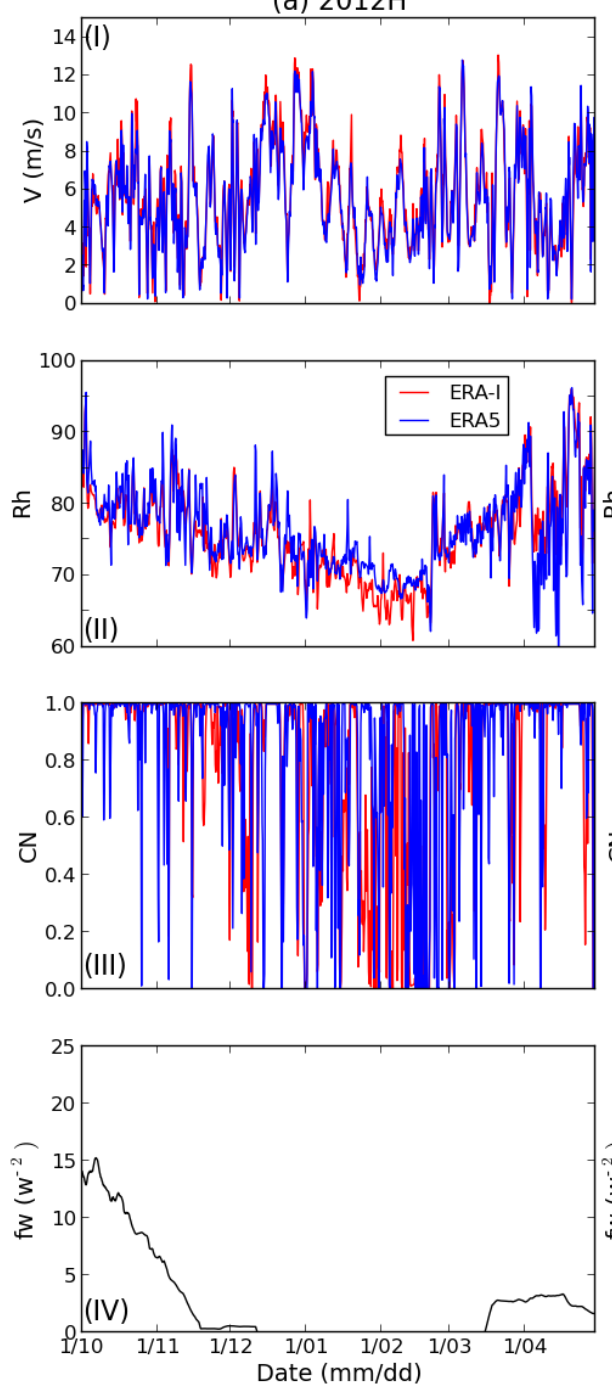

(b) $2011 \mathrm{M}$
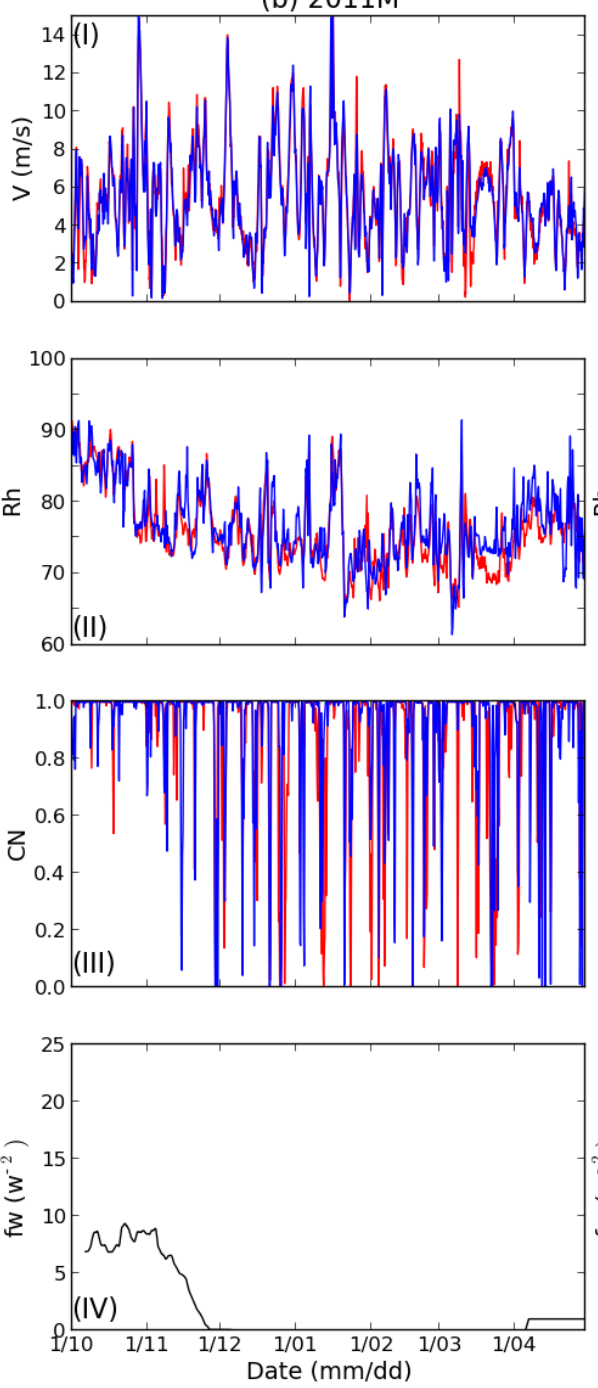

(c) $2012 \mathrm{~L}$
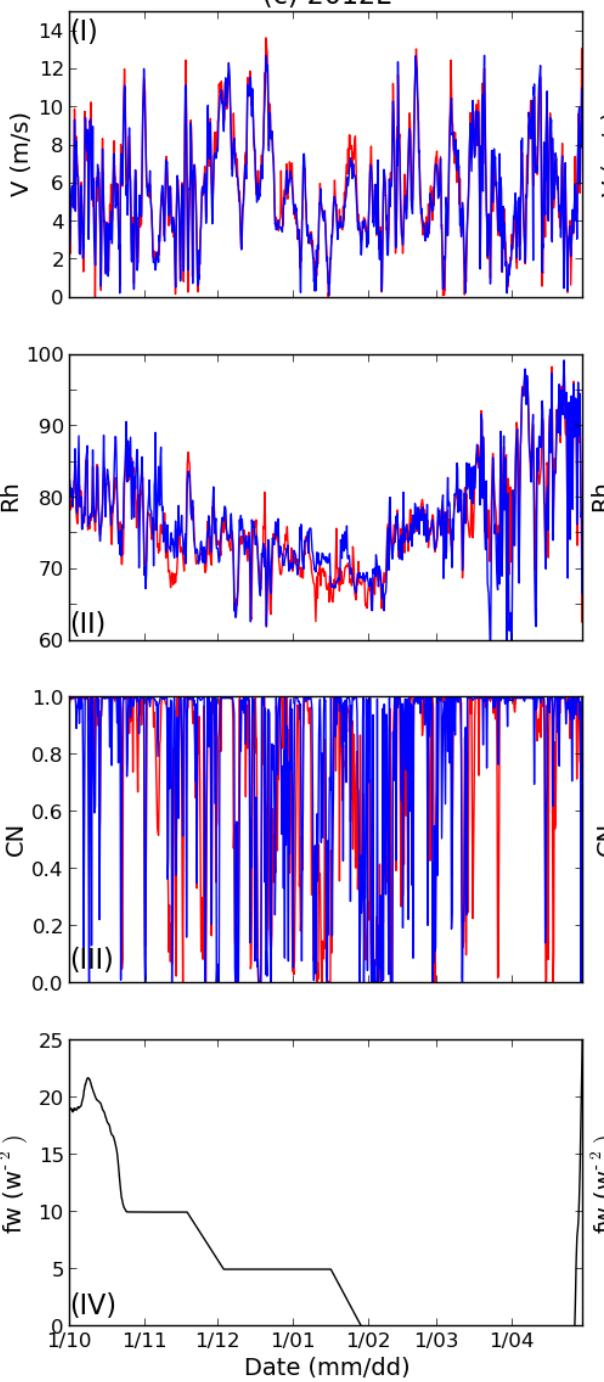

(d) 2012 J
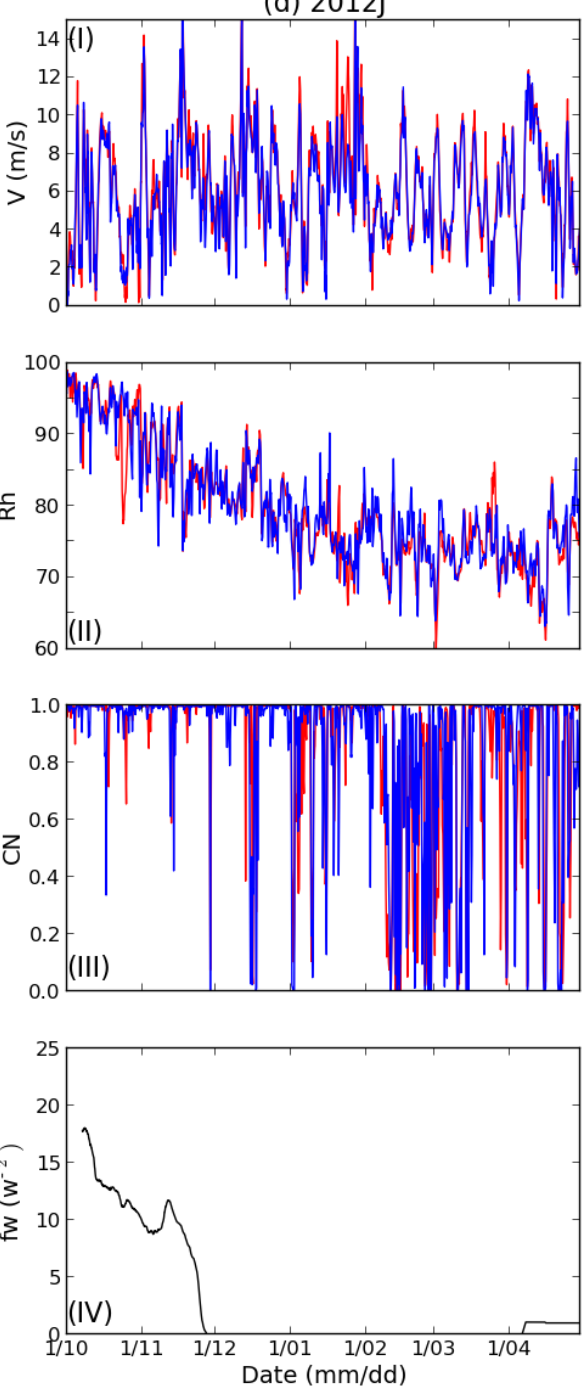

Figure S9. Forcing data of wind speed (V), relatively humidity (Rh), total cloud (CN) and ocean heat flux (fw) used in the model runs. 